\title{
Fractal characteristics and significances of the nanopores in oil shales during hydrous pyrolysis
}

\author{
Lina Sun ${ }^{1}(D)$ Deliang $\mathrm{Fu}^{2} \cdot$ Shunqi Chai ${ }^{3} \cdot$ Wenxia Yang $^{3} \cdot \mathrm{Kai} \mathrm{Zhou}^{3} \cdot \mathrm{Wei} \mathrm{Li}^{3}$
}

Received: 18 January 2019 / Accepted: 20 September 2019 / Published online: 27 September 2019

(c) The Author(s) 2019

\begin{abstract}
In order to explore the pore characterizations in shales during organic matter evolution, a series of simulation experiments were conducted. The artificial hydrous pyrolysis was conducted on the same seven columned oil-shale samples at $250{ }^{\circ} \mathrm{C}$, $300{ }^{\circ} \mathrm{C}, 350{ }^{\circ} \mathrm{C}, 375{ }^{\circ} \mathrm{C}, 400{ }^{\circ} \mathrm{C}, 450{ }^{\circ} \mathrm{C}$ and $500{ }^{\circ} \mathrm{C}$, respectively. To obtain the characteristics of pore structures in shales, the unheated and the residual solid samples were analyzed by low-pressure nitrogen adsorption method. Based on the nitrogen adsorption isotherms, fractal dimensions were calculated by the model of Frenkel-Halsey-Hill, which also contained the fractal dimension of $D_{1}$ and $D_{2}$ before and after the relative pressure $P / \mathrm{Po}=0.5$, respectively. And then the relationships of simulation temperatures (thermal maturity), total-, macro-, meso- and micro-pores volumes, specific surface areas and diameters to fractal dimensions were investigated. The results showed that the average value of $D_{2}(2.6110)$ was higher than $D_{1}(2.4147)$ and there was a positive relationship between them $\left(R^{2}=0.9237\right)$, which indicated that though $D_{2}$ and $D_{1}$ were more related to pore structures and surfaces, the better linear relationships suggested that both of them could be used in the representation of pore structures and surfaces in shales. With the thermal maturity increasing, the obvious fractal characteristics were, the complexity of pore structures were, which may be associated with the following cause-and-effect relationships. During the pyrolysis, the generation of hydrocarbons increased, as well as the consumption of TOC may increase the volume and surface area of total-, macro-, meso- and micro-pores but decrease the corresponding average diameter and then the quantities of smaller pores occurred and led to the strengthening of pore heterogeneity in shales. Based on the fractal characteristics, we also found the higher thermal maturity would result in the better connections among pores but worse permeability in shale, which further increased the gas adsorption quantity. Therefore, analyzing the fractal characteristics in shales could provide help for clarifying the characteristics of reservoirs as well as the comprehensive exploration and development of shale gas.
\end{abstract}

Keywords Oil shales $\cdot$ Hydrous pyrolysis $\cdot$ Nitrogen adsorption method $\cdot$ FHH model $\cdot$ Pore structure $\cdot$ Fractal dimension

\section{Introduction}

With the development of shale gas in the world, the studies about shale reservoirs had also become an important part (Dejam et al. 2014, 2017, 2018a, b; Zhang et al. 2018;

Lina Sun

slina16@yangtzeu.edu.cn

1 Hubei Cooperative Innovation Center of Unconventional Oil and Gas, Yangtze University, Wuhan 430100, China

2 Key Laboratory of Coal Resources Exploration and Comprehensive Utilization, Ministry of Land and Resources, Xi' an 710021, China

3 School of GeoSciences, Yangtze University, Wuhan 430100, China
Dejam 2019; He et al. 2019; Wei et al. 2019). Nanopore was an important reservoir space and seepage passage to shale gas (Tan et al. 2019; Qiu et al. 2019), and the corresponding pore structures had important influence on the storage, migration and occurrence of shale gas. Thus, the porosity could be seen as the indicator on the evaluation of shale reservoir hydrocarbon-generating potential and quality and played a significant role on researching the properties of shale reservoirs (Curtis et al. 2012; Loucks et al. 2012; Romero-Sarmiento et al. 2013). By the classification from IUPAC (International Union of Pure and Applied Chemistry) (Sing et al. 1985), the pores could be divided into micro-, meso- and macro-pores with the diameter of $0-2 \mathrm{~nm}$, $2-50 \mathrm{~nm}$ and $>50 \mathrm{~nm}$, respectively. The researches about pore structures in shale reservoirs had been studied by the 
means of actual geological conditions, and the thermal simulation experiments (Hou et al. 2014; Chalmers and Bustin 2007; Zhao et al. 2010; Mastalerz et al. 2012; Tiwari et al. 2013) were proved that the pores were affected by the OM (organic matter) evolution. Therefore, during the procedure of thermal evolution, the micro-, meso- and macro-pores would present a corresponding changing, as well as the pore size, geometry, volume, structure and connectivity (Fig. 1).

Fractal geometry was a new branch of mathematics which developed in the late 1970s to describe the irregular forms and random phenomena of things (Mandelbrot 1982). Fractal was a generic term for irregular structures and configurations with self-similarity, which was featured by the similarity between the part and the whole in a certain way. And the corresponding parameters that quantitatively described the research objects with self-similarity were called fractal dimensions (Zhang et al. 1998). The researches showed that fractal dimension could be used to characterize the complexity and heterogeneity of solid surface and pores, which already had been applied to quantitatively characterize the complexity of pore structure in coal petrography (Yao et al. 2008, 2009; Ma et al. 2012; Wang et al. 2012). Compared to coal reservoirs, the pore structures developed in shale were more complex as well as the stronger heterogeneity of reservoir. Moreover, the complex pore network in shale was difficult to be evaluated by some experimental test parameters. But the quantitative characterization of the heterogeneity of pore structure would be helpful to further understand the adsorption storage capacity of shale gas. Therefore, fractal theory was an important method to study the pore structure and quantitatively represent the heterogeneity of shale (Cai et al. 2013; Yang et al. 2014a, b; Bu et al. 2015; Wang et al. 2015). And the past research revealed that fractal dimensions, taken as the quantitative research method on the

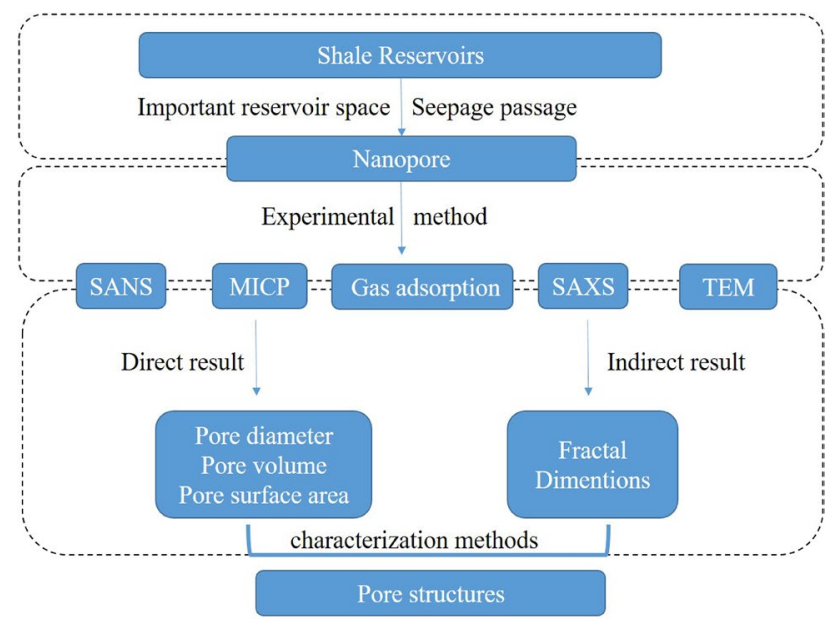

Fig. 1 The general research sketch of the pore structures complexity and heterogeneity of pore structures in shales, had been used to evaluate the pore surface roughness $(\mathrm{Bu}$ et al. 2015; Wang et al. 2015; Yao et al. 2008; Cai et al. 2013; Liu et al. 2014; Yang et al. 2014a, b). By the analysis of fractal characteristics, the pore distribution and complexity of pore structures as well as the grain composition of reservoir rock could be gained. And the methods, such as small-angle neutron scattering (SANS), mercury injection capillary pressure (MICP), small-angle X-ray scattering (SAXS), the transmission electron microscopy (TEM) image analysis and gas adsorption (Chaput et al. 1990; Craievich et al. 1988; Liang et al. 2015; Liu et al. 2015; Lours et al. 1988; Pyun and Rhee 2004; Hu et al. 2013), had been seen as the basic theory to calculate fractal dimensions. Of which, based on the gas adsorption method, the fractal dimensions were usually calculated by the method of the Brunauer-Emmett-Teller (BET) surface area analysis and Frenkel-Halsey-Hill (FHH) theory (Bu et al. 2015). With fractal theory, previous researchers had already revealed a lot of research achievements to apply to the reservoirs. Such as, some scholars pointed that the higher $\mathrm{CH}_{4}$ adsorption quantity of coals was proved by the more irregular coal surface and more homogeneous pore structure (Yao et al. 2008; Zhang et al. 2014). By the analysis on the relationship among the fractal characteristics, geochemistry parameters and pore structures of shales, one pointed that fractal dimension was positive to the corresponding TOC, pore volume and specific surface area and so forth. In addition, they also found that the effect of micro-pores to fractal dimension was bigger than the meso- and macro-ones (Yang et al. 2014a, b). In further, some scholars also discovered that when the max throat radius and average pore radius were bigger, the corresponding fractal dimension was more lower. Thus, the smooth pore surface would produce smaller resistance to hinder the flow of fluid in the reservoirs, which would result in the reduction in heterogeneity in shales.

However, the studies about the fractal characteristics of shales during $\mathrm{OM}$ evolution were fewer. Therefore, the fractal characteristics of the nanopores in shales during thermal evolution should be investigated. Thus, we would carry out this research from the following aspects. First, the samples were from the hydrous pyrolysis experiments and they could be seen as the "original samples" at different thermal evolution levels. Second, the calculation of fractal dimensions is based on the nitrogen adsorption isotherm of solid residues from pyrolysis experiments and the FHH model, in which the pore size distribution and fractal characteristics of shales would be gained. Third, the results would be discussed among pores structures, $\mathrm{OM}$ evolution and fractal parameters.

In further, the influence factors of fractal dimension would be explored, which was expected to provide help for 
clarifying the characteristics of reservoirs as well as the comprehensive exploration and development of shale gas in this area.

\section{Methods}

\section{Samples and pyrolysis experiments}

The purpose of this paper was to discuss the fractal characteristics during OM evolution, so the samples were used in pyrolysis experiments. The block sample was collected from Chang 7 Yanchang Formation, Triassic, Ordos Basin, Western China. The oil-shale sample had the following characteristics; TOC was $13.75 \%$; HI (hydrocarbon index) was $483.49 \mathrm{mg} / \mathrm{g}$ TOC; OI (oxygen index) was $0.95 \mathrm{mg} / \mathrm{g}$ TOC; $\mathrm{T}$-max was $451^{\circ} \mathrm{C}$; the type of kerogen was Type I-II; and the thermal maturity was early mature to mature. As the experimental procedures used in this article had also been described in detail previously (Sun et al. 2015), the sample information, experiment principle, experimental procedure, experimental results, pyrolysis products yields and pore structures characteristics were available in the previous reference (Sun et al. 2015). Then, these experimental procedures were listed and summarized briefly below.

The block sample was drilled into columned samples (length: 4-5 cm; diameter: $2.5 \mathrm{~cm}$ ) prepared for pyrolysis. The instrument of WYMN-3 HTHP (high temperature high pressure) was used in the pyrolysis experiments, and the corresponding experimental procedure was listed below: (1) There were 7 temperatures: $250{ }^{\circ} \mathrm{C}, 300{ }^{\circ} \mathrm{C}, 350{ }^{\circ} \mathrm{C}, 375^{\circ} \mathrm{C}$, $400{ }^{\circ} \mathrm{C}, 450{ }^{\circ} \mathrm{C}$ and $500{ }^{\circ} \mathrm{C}$ points were conducted in this series of experiments. (2) Experimental time will take $2 \mathrm{~h}$ to rise from the room temperature to the target temperature and then hold at the target temperature for $48 \mathrm{~h}$. (3) The other experimental conditions, such as lithostatic pressure and hydrodynamic pressure, were all same in the 7 experiments.

\section{Calculation of the fractal dimension}

ASAP 2020 HD88 surface area analyzer was used to analyze the extracted solid residues (Sun et al. 2015), and then we could gain the low-pressure nitrogen adsorption isotherms data. Based on these data, we could calculate the parameters of the fractal dimensions.

The FHH model was used in this research, and the calculation equation of FHH model could be described as below (Ahmad et al. 2006):

$V / \mathrm{Vo}=K[\ln (\mathrm{Po} / P)]^{D-3}$

where $V$ and $V o$ are the volume of the sorbed gas at equilibrium pressure and monolayer coverage $\left[\mathrm{cm}^{3} / \mathrm{g}\right.$, standard temperature and pressure (STP)], respectively; $K$ is the constant; Po and $P$ are the pressure of gas saturation and balance pressure $(P a)$, respectively; $D$ is the fractal dimension value. Equation (1) could be converted into the $\log -\log$ terms, which is:

$\ln V=C+(D-3) \ln (\ln (\mathrm{Po} / P))$

in which $\ln V$ was positive to $\ln (\ln (\mathrm{Po} / P))$. Thus, when we plot the straight line of $\ln V-\ln (\ln (\mathrm{Po} / P))$, the slope $(K$, which was represented by linear coefficient) should be equal to the coefficient of $(D-3)$, so we could calculate the fractal dimension of $D$ by the following equation:

$D=K+3$

which was only one of the calculation equation, and another was $D=3 K+3$ (Avnir and Jaroniec 1989), but the formula of $D=K+3$ was used in our research.

\section{Results and discussion}

\section{Pore fractal dimension}

We could get the value of $D$ based on the known $K$ and Eq. (3) (Fig. 2 and Table 1). For the higher $R^{2}$ (determination coefficients) occurred in the fractal fitting equation, there were fractal characteristics in these samples. As previous studies showed that the value of $D$ was generally ranged from 2 to 3 (Wang et al. 2015; Yao et al. 2008; Yang et al. 2014b) and the rougher of materials surface areas were, the higher $D$ was within this range. Thus, if the value of $D$ was bigger and closer to 3 , the heterogeneity was stronger in shale.

However, as there were different curves of adsorption and desorption occurred at about $P / \mathrm{Po}=0.5$ (Sun et al. 2015), we could divided the curves into two parts. When $P / P o=0-0.5$, the curves of adsorption and desorption were practical unanimity and then the hysteresis loops often occurred after $P /$ $\mathrm{Po}=0.5$ (Bu et al. 2015; Wang et al. 2015; Yao et al. 2008). Thus, we would also get two fractal dimensions before and after $P / \mathrm{Po}=0.5$, which were the fractal dimension $D_{1}(P /$ $\mathrm{Po}=0-0.5)$ and $D_{2}(P / \mathrm{Po}=0.5-1)$, respectively. Both of the $R^{2}$ in the segment of before and after $P / \mathrm{Po}=0.5$ were $>0.9$, which proved the feasibility based on the FHH model to analyze the pore structures in these pyrolysis samples. In addition, the different fractal characteristics occurred at these two segments were also found (Pyun and Rhee 2004). On one aspect, the quantity adsorbed gas was higher before $P / \mathrm{Po}=0.5$ than the after ones, which inferred to the bigger pores in the former segment. On the other aspect, the value of $D_{2}$ ranged from 2.5146 to 2.7355 with the average value of 2.6110, which was higher than $D_{1}$ (2.2434-2.7174, average value was 2.4147 ). Thus, we could gain the conclusion that the smaller pores were more homogeneous than

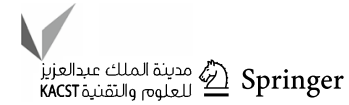




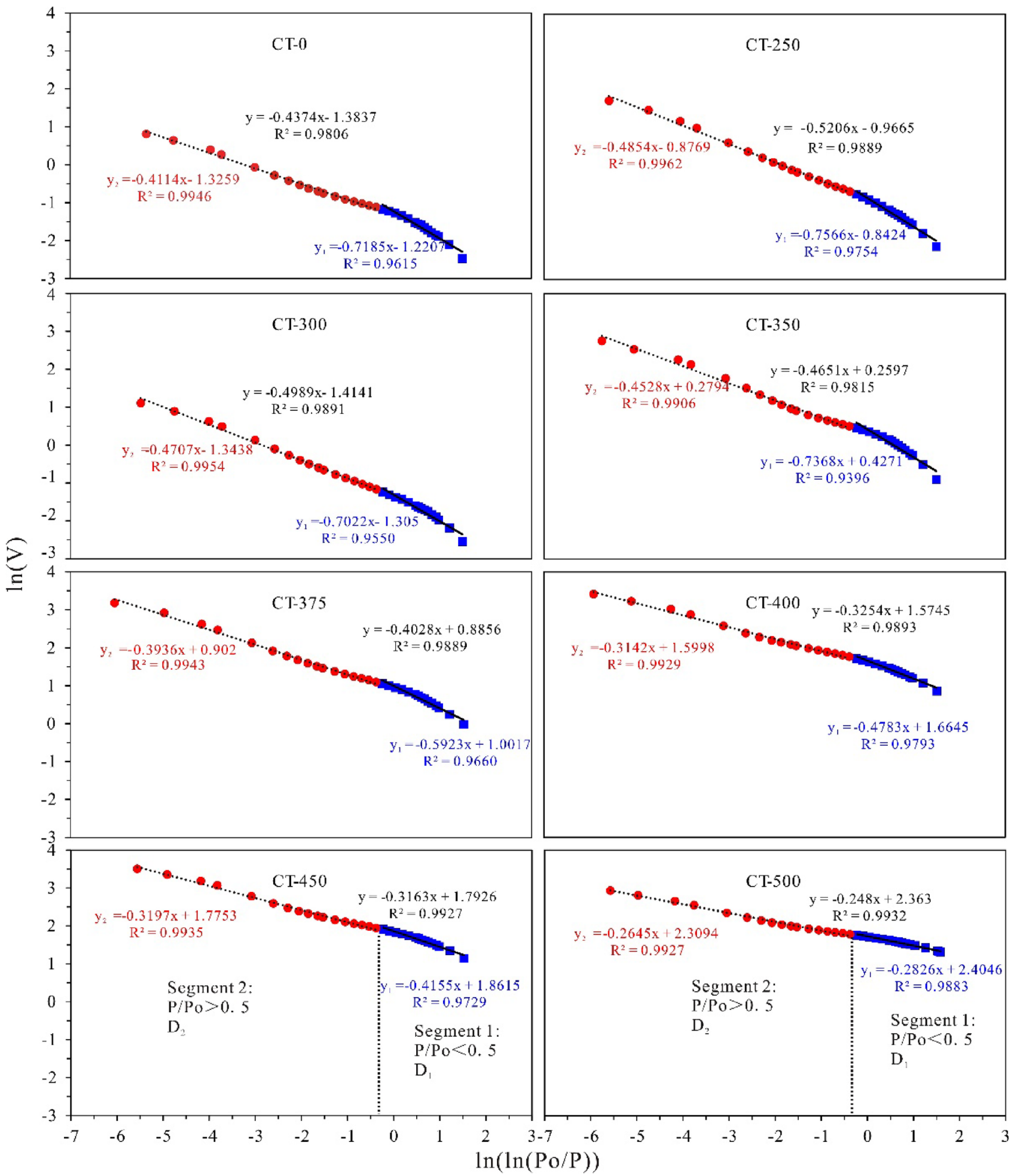

Fig. 2 Plots of $\ln (V)$ versus $\ln \ln (\mathrm{Po} / P)$ based on the nitrogen adsorption isotherms. CT-0 represents the original sample; CT-250, 300, $350,375,400,450$ and 500 represent the different simulation tem- perature samples. Fitting equations of $y, y_{1}$ and $y_{2}$ correspond to the fractal dimensions of $D(P / \mathrm{Po}: 0-1), D_{1}(P / \mathrm{Po}: 0-0.5)$ and $D_{2}(P / \mathrm{Po}$ : $0.5-1)$, respectively 


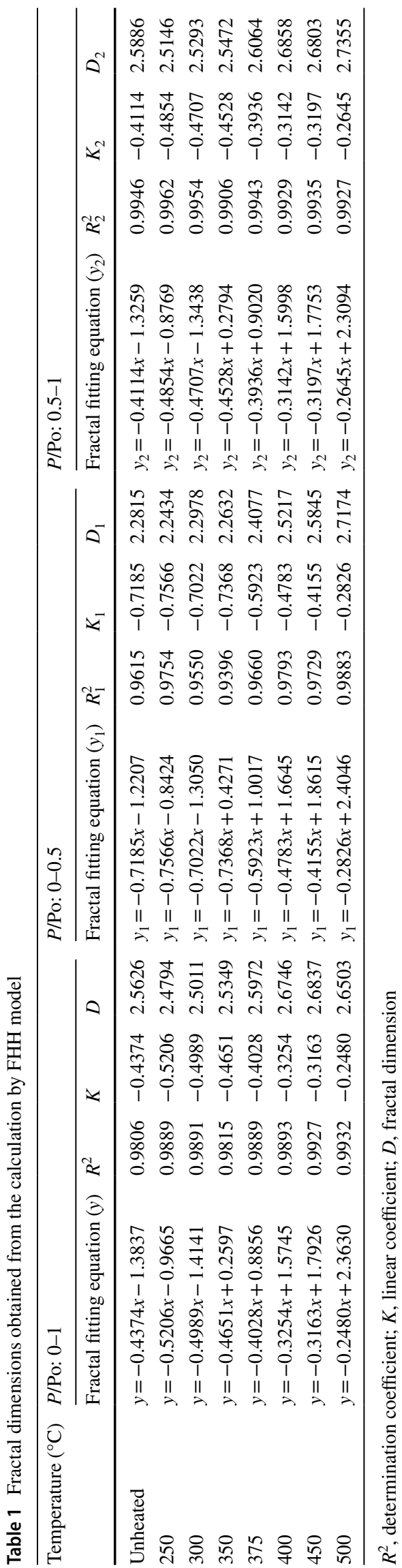

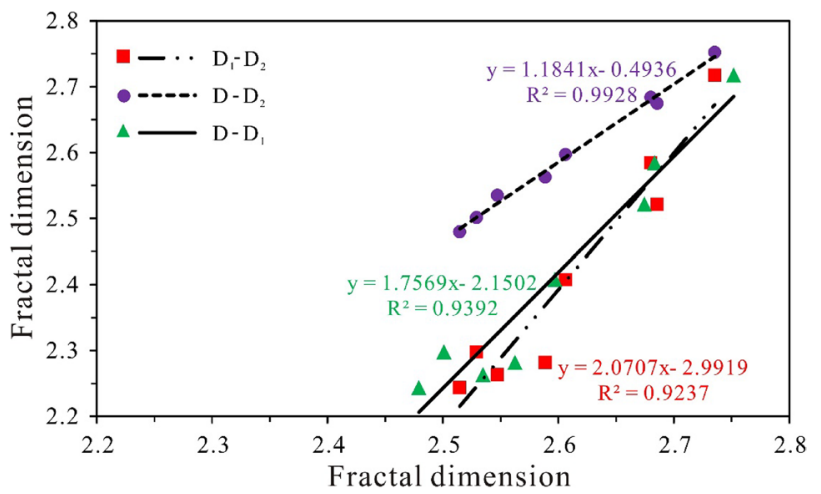

Fig. 3 Linear relationships of fractal dimension $D-D_{1}, D-D_{2}$ and $D_{1}-$ $\mathrm{D}_{2}$ in pyrolyzed oil shales

the bigger ones. Meanwhile, the formers also found the different isotherms occurred before and after $P / \mathrm{Po}=0.5$. When the $P / \mathrm{Po}<0.5$, Van der Waals forces controlled the gas-solid interface and the forming of hysteresis loop was associated with the meso-pore structures, which was defined as monolayer adsorption region and characterized by micropores filling (Yao et al. 2008; Pyun and Rhee 2004; Khalili et al. 2000). When the $P / \mathrm{Po}>0.5$, capillary condensations dominated the liquid-gas interface, which was defined as multilayer adsorption region and characterized with bottleshaped meso-, macro-pores filling (Pyun and Rhee 2004; Khalili et al. 2000; Qi et al. 2002; Sing 2004). Hence, when $P / \mathrm{Po}<0.5, D_{1}$ was mainly controlled by the action of Van der Waals forces and represented the surface fractal dimension. When $P / \mathrm{Po}>0.5, D_{2}$ was mainly dominated by the action of capillary condensation and represented the pore structure fractal dimensions. $D_{1}$ was positive to $D_{2}$ in this study (Table 1 and Fig. 3), which was different from the previous research (Yao et al. 2008). So that $D_{1}$ and $D_{2}$ may all represent both the pore surfaces and structures characterizations of these pyrolysis samples. As the positive correlation lied in $D_{1}-D_{2}, D-D_{1}$ and $D-D_{2}$ with the determination coefficients of $0.9237,0.9928$ and 0.9392 , respectively (Fig. 3), $D$ was more associated with $D_{1}$. So, in the following parts, we would only discuss the correlations of $D_{1}$ and $D_{2}$ with the other influence factors.

\section{Response of the fractal dimension to temperature}

From Table 1 and Fig. 4, without the point of original samples, there was a better linear relationship between simulation temperature and fractal dimension $\left(D_{1}\right.$ and $\left.D_{2}\right)$ with the $R^{2}$ of 0.8898 and 0.8956 , respectively. But $R^{2}$ were decreased to 0.8028 and 0.6545 when the original point was added. Namely, from $250{ }^{\circ} \mathrm{C}$ to $500{ }^{\circ} \mathrm{C}, D_{1}$ and $D_{2}$ all presented an increasing tendency, but decreased from the unheated sample to $250{ }^{\circ} \mathrm{C}$. So, when the original sample was heated, its 


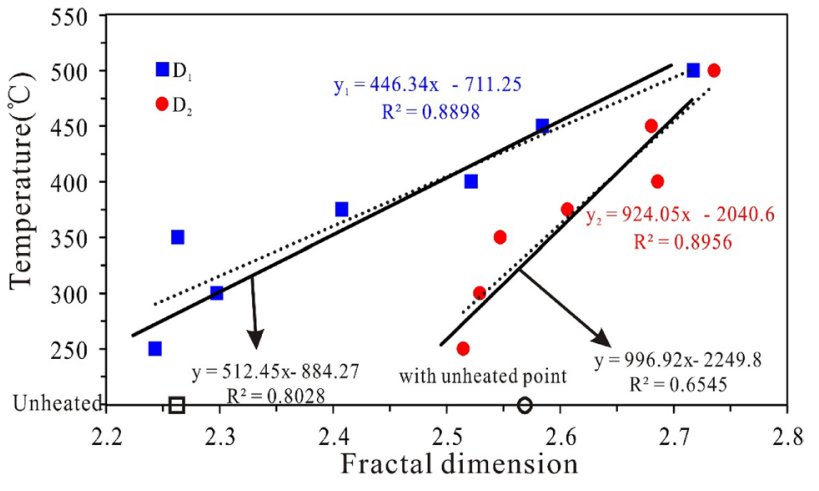

Fig. 4 Relationships between fractal dimensions and simulation temperatures in pyrolyzed oil shales

surface turned more smoothly and mainly affected $D_{2}$. Actually, in Table $1, D_{2}$ of unheated sample ( $D_{2}$-unheated) was higher than that at $250{ }^{\circ} \mathrm{C}, 300{ }^{\circ} \mathrm{C}$ and $350{ }^{\circ} \mathrm{C}$ points. While before $350^{\circ} \mathrm{C}$, which was exactly the stage before "oil-generating window" and the yields of expelled oil were lower (Sun et al. 2015). So the following interpretations may be gained: (1) in the lower thermal stage, the forming of hydrocarbons promoted the pore connectivity and decreased the roughness of shales; (2) the preferential generation of resin and asphaltene may block the more complicated "branch" pores and vacate the "main" pores, which may reduce the complexity of pore structures and the corresponding fractal dimensions.

However, with the simulation temperature increasing, TOC was reduced and the corresponding pore volumes were increased, which resulted in the increase in fractal dimensions. Namely, the generation of hydrocarbons increased the complexity degree of oil shales during the process of pyrolysis. The complexity of pore structures in shale reservoir was depended on its physical properties, especially for the features of porosity and permeability. Total pore volumes could be seen as the important indicator to porosity. The changing characteristic features of the pore volume and specific area to the increasing simulation temperature were studied in the previous article (Sun et al. 2015), and the positive correlations between them were obtained. So, the thermal maturity could affect the generation and expelling of hydrocarbons, as well as the fractal dimensions. In details, the simulation temperature affected the hydrocarbons generated and TOC consumed, which then increased the pore volumes and specific surface areas but decreased the average diameter, next followed by the increasing quantities of pores, and finally resulted in the increase in fractal dimensions. Therefore, the simulation temperature would increase the values of fractal dimensions directly. Then, conversely, based on the numerical magnitude of fractal dimensions values, the thermal maturity also could be indicated during OM evolution.

\section{Response of the fractal dimension to pore structure}

\section{Relationships between pore volumes and fractal dimension}

In Fig. 5a, from 250 to $500{ }^{\circ} \mathrm{C}, D_{1}$ and $D_{2}$ all increased with the pore volumes. As the strongly positive correlations occurred between $D_{1}, D_{2}$ and total pore volumes with the $R^{2}$ of 0.9072 and 0.9551 , respectively. So the development of pores would result in the increase in pore fractal dimension. And the better developed pores, the bigger of fractal dimension as well as the more strong heterogeneity of pores in shales during thermal evolution. But the results were better than the studies before (Wang et al. 2015), which showed that the pore volume only had some influences on fractal dimensions. Actually, the samples pyrolyzed in this article were columns at different simulation temperatures from the same original sample, but the 21 different lacustrine shale core samples were obtained from the actual geologic profiles in that research (Wang et al. 2015). Therefore, the different types of samples were the one reason, and another may be affected by different thermal evolution stages.

The relationships of micro-, meso- and marco-pores with fractal dimensions are also shown in Fig. 5b-d. The $R^{2}$ of $D_{2}$ were all higher than $D_{1}$, though both of them all reached above 0.84 . This phenomenon indicated the increasing micro-, meso- and marco-pores would all influence the roughness of pores as well as prove that $D_{2}$ was more significantly related to the pore structure characteristics (Bu et al. 2015; Yao et al. 2008). And as the previous research pointed, pore volume almost had no correlation with $D_{1}$ and $D_{2}$ in the different actual geological samples (Bu et al. 2015), which was also different from our studies in this article. Therefore, we could gain the conclusion that the increased pore volume during OM evolution could result in the increase in fractal dimensions.

\section{Relationships between pore surface areas and fractal dimension}

The correlation between fractal dimension and specific surface areas is illustrated in Fig. 6. The better relationships occurred between fractal dimensions and total-, micro-, meso-, macro-pores indicated that the increasing surface areas would also result in the more rough surfaces of pores in pyrolysis samples. Thus, the micro-, meso- and macropores could all affect the values of $D_{1}$ and $D_{2}$ and also further lead to the more complexity of pore structures. In general, in a given pore volume, there was a negative linear relationship between pore diameter and specific surface area (Chalmers and Bustin 2008). Therefore, if the pore volume was constant, the increased surface area would be resulted in the decrease in pore diameter, which may prove that the smaller pores were more related to the fractal dimensions 


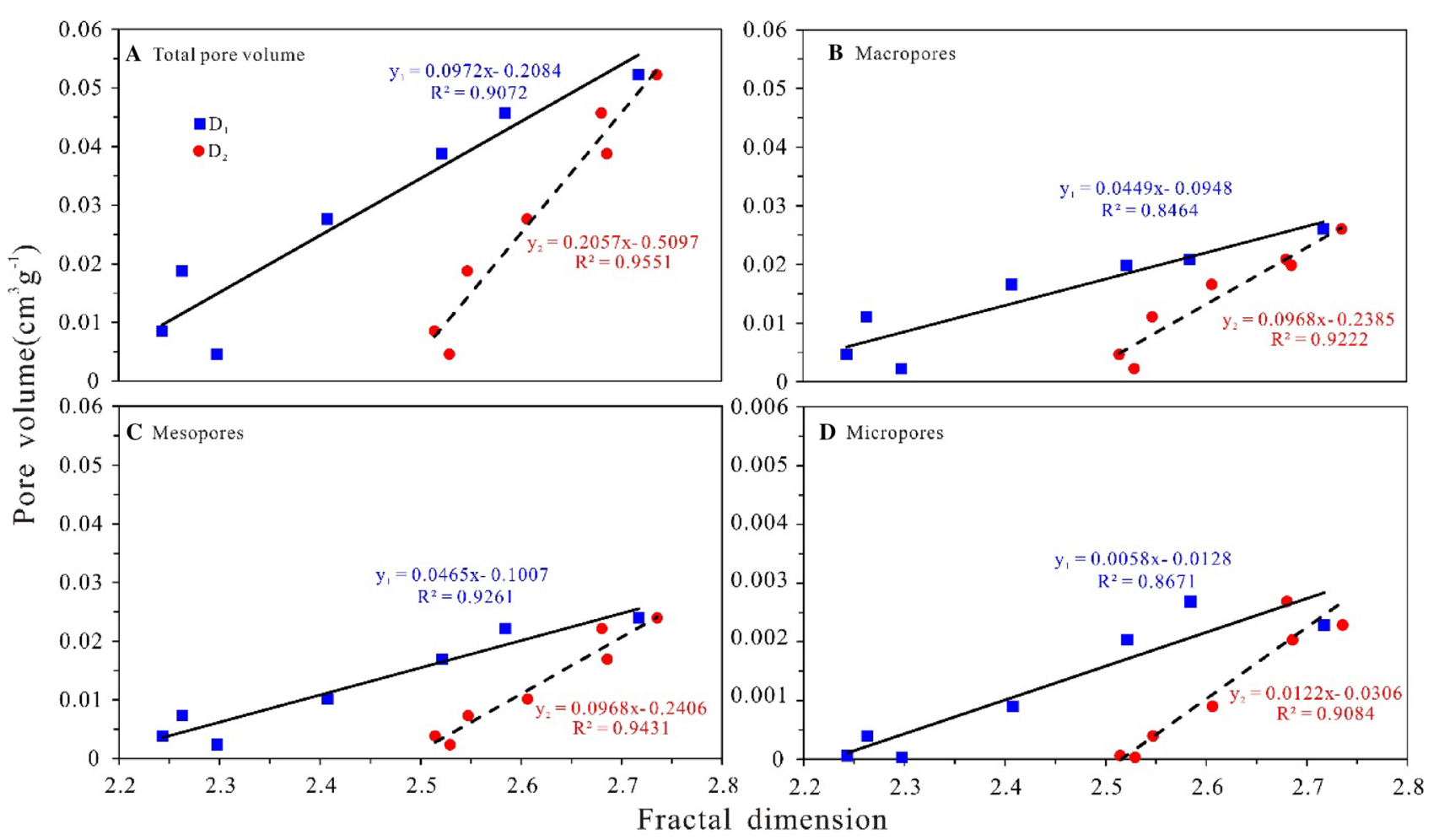

Fig. 5 Relationships between fractal dimensions and pore volumes in pyrolyzed oil shales
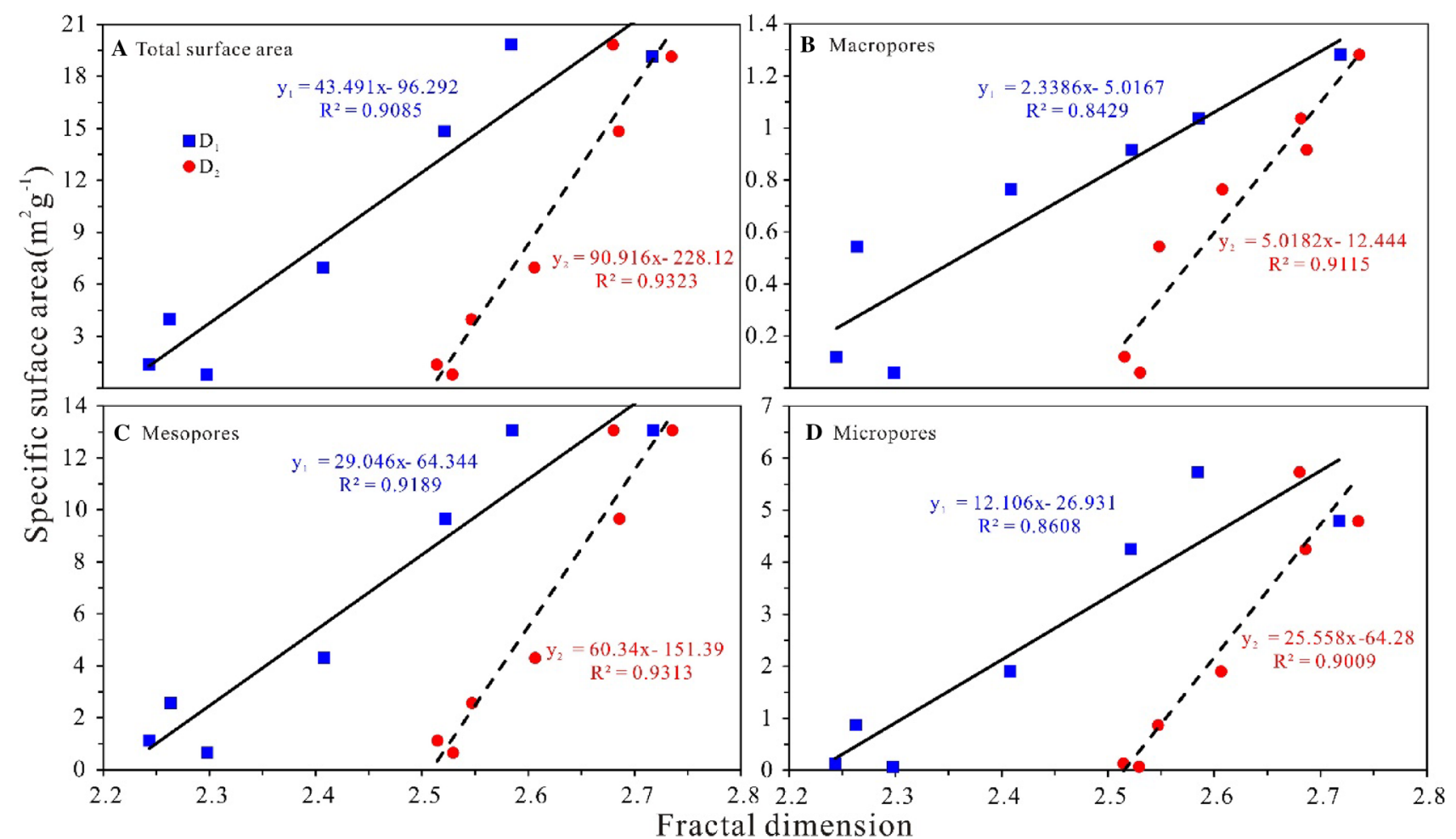

Fig. 6 Relationships between fractal dimensions and pore specific surface areas in pyrolyzed oil shales 
than the bigger ones. In terms to the values of $D_{1}$ and $D_{2}$, the $R^{2}$ in $D_{1}$ were all smaller than $D_{2}$, so $D_{2}$ were more suitable to describe the pore structure properties in these pyrolyzed samples (Bu et al. 2015; Yao et al. 2008).

\section{Relationships between pore diameters and fractal dimension}

In Fig. 7a, fractal dimensions increased with the decreasing total average diameters of total pores, which presented that the effects of smaller pores on the complexity of pores were greater than the larger ones. The average diameters of macro- and meso-pores had a negative correlation with fractal dimensions, and the correlation was better in the meso-pores than the macro-pores. Thus, we could consider that the smaller pores were more related to the heterogeneity of pore structures than the larger ones. The correlations of determination values of $D_{1}$ were higher than $D_{2}$, which were in consistent with the results in total pore volumes and specific surface areas. So it could also prove the stronger representations of $D_{2}$ to pore structures than $D_{1}$.

Then, diameters of micro-pores presented a good linear relativity with fractal dimension, though the coefficients of determination were only about 0.6 and not well higher enough. The average diameters of micro-pores were almost not changed from 250 to $500^{\circ} \mathrm{C}$. But as the fractal dimensions increased, this may be caused by the increasing quantities of micro-pores.

\section{Relationships among pore volumes, surface areas and average diameters to fractal dimension}

Combining the above three parts together, with the total pore volumes and specific surface areas increased, the fractal characteristics of pores were more obvious. But the opposite situations occurred for the bigger pore diameters. As what we had studied that there were a certain number of macro-, meso- and micro-pores formed with the increasing simulation temperature from 250 to $500{ }^{\circ} \mathrm{C}$, with the decrease in average meso-, macro-pores diameters and the almost invariable micro-pores diameters (Sun et al. 2015). This meant that the formation of smaller pores increased the roughness of pores, but not only the effects of micro-pores during thermal evolution. Namely, not only the micro-pores could affect the fractal dimensions, but also the increased quantities of meso- and macro-pores. And in details, cause-and-effect relationships were listed in order from left to right, the later was caused by the former one. They were, the simulation temperature increased, the thermal maturity increased, the hydrocarbons expelled, the total pore volumes and surface areas increased, but the average diameters decreased, the quantities of pores increased, and the fractal dimensions of pores increased. Therefore, the immediate causes for the
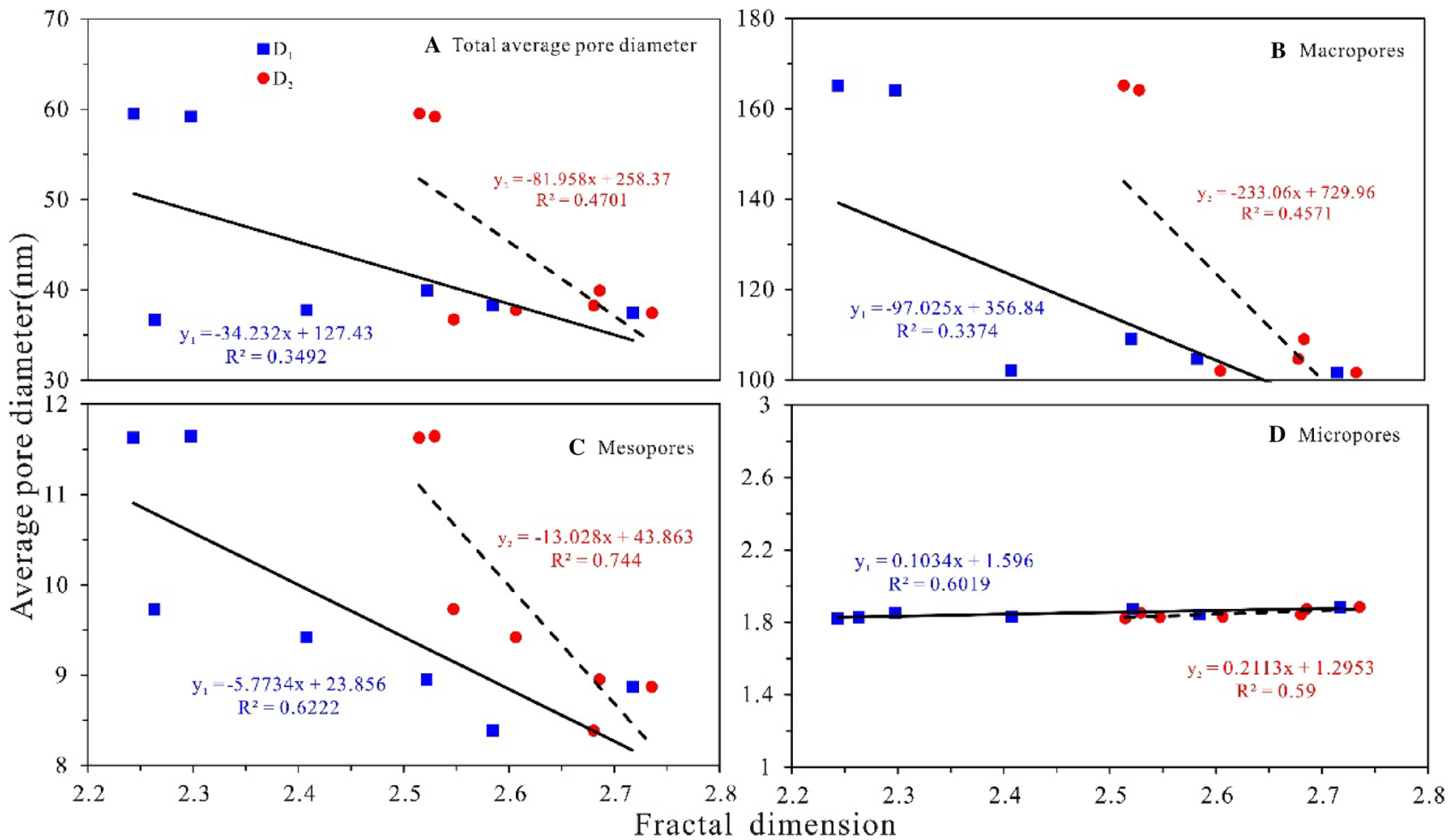

Fig. 7 Relationships between fractal dimensions and average pore diameters in pyrolyzed oil shales 
heterogeneity of oil shales were the increasing quantities of pores. Namely, the quantity irregular surfaces resulted in the higher fractal dimensions values, which increased the gas adsorption. This cognition could also be used in the results by previous researchers, who though that the main effects on fractal dimensions were the micro-pores but not the mesoand macro-pores (Bu et al. 2015; Wang et al. 2015; Yang et al. 2014b). This phenomenon may be considered as the transforming from meso-, macro-pores to micro-pores and then resulting in the increased numbers of micro-pores.

\section{Relationships between generated hydrocarbons and the fractal dimension}

Pores could be seen as the reservoir space and migration pathway for the generated products. As the column source rocks samples with the original pore structures were used in these experiments, the pores characteristics with the increasing temperatures may also provide some evidences to the $\mathrm{OM}$ evolution. The same original column samples and other experiment conditions indicated that the major driving force of the hydrocarbons migration was the different hydrocarbon concentrations within and outside the source rock. Then, the size of accumulation space within the column samples would also affect the migration of hydrocarbons, and this may mainly be affected by the pore structures. While the temperature increased, the pore volumes, surface areas and pore dimensions values were also increased with the simulated temperatures, so the smaller pores and much rougher of the pore surface were. Thus, this feature may be compared by that two wide roads were rebuilt into many narrow roads. Therefore, in lower maturity, the generated hydrocarbons were smaller, and they could be expelled from the reaction systems without destroying the reformed pores. And the parts stored in the pores were fewer for the smaller adsorption capacity and less heterogeneity in shales. However, in higher maturity, the size of pores was deceased with the increasing surface areas and fractal dimension values. So the smaller pores would provide more chances for gas to be adsorbed and then result in the decreasing yields of gaseous hydrocarbons. Actually, in higher simulation temperature, the liquid, gaseous hydrocarbons as well as the added water were all in the form of gaseity, so they all could be adsorbed in the pores. And then after pyrolysis at room temperature, the parts of liquid hydrocarbons and water could be liquefied and then volatilized. Namely, the collected liquid and gaseous hydrocarbons were lower than the actual yields, which were more pronounced at higher maturity. And, at the same time, the heterogeneity in shales was much stronger at higher maturity. Therefore, on the one hand, the higher fractal dimension values may indicate that the higher gas adsorption, maturity and losing generated hydrocarbons. On the other hand, the lower yields of generated liquid hydrocarbons at higher maturity were both associated with secondary cracking of liquid hydrocarbons to gaseous ones and the larger adsorption in more porous and rougher shales.

\section{Research significance of the fractal dimension}

The discussions above were all about the effects of simulation temperature, pore structure, surface area and diameter on the fractal dimension. Then in contrary, if the values of fractal dimensions had been known, what features of thermal maturity, pore structures in shales could be gained? Fractal dimension, a numerical value, presented a visual indicator to the homogeneity of pores in shales. The higher fractal dimension indicated the smaller pore diameters and higher pore quantities; thus, the corresponding adsorbed capacity of $\mathrm{CH}_{4}$ would also increase, because in a given volume, there was a negative linear relationship between surface area and diameter. And as the diameter decreased, the corresponding surface areas increased, which offered more contact areas for adsorbed gas. This may be the first reason and significance, which was consistent with the former studies (Yang et al. 2014a, b). Then, on the other hand, we had pointed out that there may be a better connection in pores at higher thermal evolution stage than the lower part (Sun et al. 2015), which was followed by the higher pore volumes and expelled hydrocarbons. Thus, when combined this result with fractal dimensions together, the conclusion that a better connection in pores may increase the heterogeneity of pores in shales could be gained. But this cognition was seemed to be against with the previous researches (Yang et al. 2014a, b), who considered that there was a negative relationship between fractal dimension and permeability. This phenomenon may be related to the more micro-pores contained in shales than the macro-pores. In addition, based on the results of decreased average diameters of macro-, meso-pores and the increased quantities of macro-, meso- and micro-pores, we may speculate that the diameters of pore throats also decreased, but their volumes and surface areas increased. Thus, there was a possibility that the connections among them may be much better, but the decrease in pore and pore-throat diameters may result in the lower permeability of pores in shales. Therefore, the higher fractal dimensions values may also indicate the smaller diameter of pore throat and the lower permeability in shales, but increased the adsorption quantity of gas.

Based on the values of fractal dimensions, the size and distribution characteristics of pores could be represented as well as the reservoir heterogeneity in shales. Then, as fractal dimensions values could also indicate the higher gas adsorption and maturity, the expelled yields of liquid and gaseous hydrocarbons may also be affected to decrease in higher maturity and the adsorption gas was prior to preserve in shale gas reservoirs. Therefore, the researches on

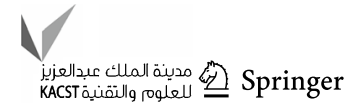


fractal characteristics were important to the understandings of shales, which played a critical role on the properties of shale reservoirs.

\section{Conclusions}

Based on the nitrogen adsorption measurement about the oil shales residues from hydrous pyrolysis at $250{ }^{\circ} \mathrm{C}, 300{ }^{\circ} \mathrm{C}$, $350{ }^{\circ} \mathrm{C}, 375{ }^{\circ} \mathrm{C}, 400{ }^{\circ} \mathrm{C}, 450{ }^{\circ} \mathrm{C}$ and $500{ }^{\circ} \mathrm{C}$ points, $\mathrm{FHH}$ model was used to calculate the fractal dimensions; the conclusions were listed as below:

(1) The higher fractal dimension value of $D_{2}$ (from 2.5146 to 2.7355 , with an average value of 2.6110 , and the range of corresponding $P /$ Po was $0.5-1$ ) than $D_{1}$ (from 2.2434 to 2.7174 , with an average value of 2.4147 , and the range of corresponding $P /$ Po was $0-0.5$ ) at every temperature point indicated that the heterogeneity of larger pores was stronger than the smaller ones.

(2) $D_{1}$ was seen as the better indicator in representing the features of pore surfaces, but the pore structures characteristics for $D_{2}$. The better positive linear relationship between them suggested that both $D_{1}$ and $D_{2}$ could represent the properties of pore surfaces and structures in oil shales during OM evolution.

(3) The fractal dimensions decreased when the original sample was heated. $D_{2}$ was higher than the point before $350{ }^{\circ} \mathrm{C}$, which exactly was the thermal stage of "oil-generating window." Thus, the lower generated hydrocarbons and (or) blocked pores by the preferential generation of resin and asphaltene may decrease the roughness of pores in shales.

(4) The simulation temperature, total-, micro-, meso-, macro-pores volumes and specific surface areas were all present a positive correlation to fractal dimensions. The average diameters of total-, meso- and macropores were negative to fractal dimensions. Thus, the increased thermal maturity, pore volume and surface areas, as well as the decreased pore diameters resulted in the increase in fractal dimensions in oil shales. And there may be a cause-and-effect relationship among them; the thermal maturity affected the OM evolution, which results in the expelling of hydrocarbons and the consuming of $\mathrm{OM}$, then further resulted in increase in pore volume and surface area but decrease in pore diameter, and next resulted in the increasing quantities of smaller pores, and finally increased the fractal dimensions in oil shales. In addition, in contrast, based on the fractal characteristics, the information about thermal maturity and pore structures may also be gained.
(5) Not only micro-pores affected the fractal dimensions, but also the changing of bigger pores to smaller ones during $\mathrm{OM}$ evolution.

6) The higher fractal dimensions occurred in shales during thermal evolution stages; the smaller the diameter of pore throat, the lower the permeability in shales would be. But the corresponding adsorption quantities of gases would be increased.

Acknowledgements This research was supported by the National Natural Science Foundation of China (Grant Nos.: 41672127, 41602151, 41903060), the Key Laboratory Project of Gansu Province (Grant No. SZDKFJJ20160504) and Natural Science Foundation Project of Hubei province (No. 2018CFB389).

Open Access This article is distributed under the terms of the Creative Commons Attribution 4.0 International License (http://creativeco mmons.org/licenses/by/4.0/), which permits unrestricted use, distribution, and reproduction in any medium, provided you give appropriate credit to the original author(s) and the source, provide a link to the Creative Commons license, and indicate if changes were made.

\section{References}

Ahmad AL, Idrus NF, Abd Shukor SR (2006) Surface fractal dimension of perovskite-doped alumina membrane: influence of calcining temperature. J Am Ceram Soc 89(5):1694-1698

Avnir D, Jaroniec M (1989) An isotherm equation for assorption on fractal surfaces of heterogenous porous materials. Langmuir 5(6):1431-1433

Bu H, Ju Y, Tan J, Wang G, Li X (2015) Fractal characteristics of pores in non-marine shales from the Huainan coalfield, eastern China. J Nat Gas Sci Eng 24:166-177

Cai Y, Liu D, Pan Z, Yao Y, Li J, Qiu Y (2013) Pore structure and its impact on $\mathrm{CH}_{4}$ adsorption capacity and flow capability of bituminous and subbituminous coals from Northeast China. Fuel 103:258-268

Chalmers GRL, Bustin RM (2007) The organic matter distribution and methane capacity of the Lower Cretaceous strata of Northeastern British Columbia, Canada. Int J Coal Geol 70(1-3):223-239

Chalmers GRL, Bustin RM (2008) Lower cretaceous gas shales in northeastern British Columbia, Part I: geological controls on methane sorption capacity. Bull Can Pet Geol 56(1):1-21

Chaput F, Boilot JP, Dauger A, Geyer AD (1990) Self similarity of alumino-silicate aerogels. J Non Cryst Solids 116(2-3):133-139

Craievich A, Dos Santos DI, Aegerter M, Lours T, Zarzycki J (1988) Structural study of fractal silica humid gels. J Non Cryst Solids 100(1-3):424-428

Curtis ME, Cardottb BJ, Sondergelda CH, Rai CS (2012) Development of organic porosity in the Woodford Shale with increasing thermal maturity. Int J Coal Geol 103:26-31

Dejam M (2019) Advective-diffusive-reactive solute transport due to non-Newtonian fluid flows in a fracture surrounded by a tight porous medium. Int J Heat Mass Transf 128:1307-1321

Dejam M, Hassanzadeh H, Chen Z (2014) Shear dispersion in a fracture with porous walls. Adv Water Resour 74:14-25

Dejam M, Hassanzadeh H, Chen Z (2017) Pre-darcy flow in porous media. Water Resour Res 53(10):8187-8210 
Dejam M, Hassanzadeh H, Chen Z (2018a) Shear dispersion in a rough-walled fracture. Soc Pet Eng J 23(5):1669-1688

Dejam M, Hassanzadeh H, Chen Z (2018b) Semi-analytical solution for pressure transient analysis of a hydraulically fractured vertical well in a bounded dual-porosity reservoir. J Hydrol 565:289-301

He L, Mei H, Hu X, Dejam M, Kou Z, Zhang M (2019) Advanced flowing material balance to determine original gas-in-place of shale gas considering adsorption hysteresis. SPE Reserv Eval Eng. https ://doi.org/10.2118/195581-PA

Hou Y, He S, Yi J, Zhang B, Chen X, Wang Y, Zhang J, Cheng C (2014) Effect of pore structure on methane sorption potential of shales. Pet Explor Dev 41(2):272-281

Hu L, Zhu Y, Chen S, Du Z (2013) Fractal characteristics of shale pore structure of Longmaxi Formation in Shuanghe area in sourthern Sichuan. Xinjiang Pet Geol 34(1):79-82

Khalili NR, Pan M, Sandı́ G (2000) Determination of fractal dimensions of solid carbons from gas and liquid phase adsorption isotherms. Carbon 38(4):573-588

Liang L, Xiong J, Liu X (2015) An investigation of the fractal characteristics of the Upper Ordovician Wufeng Formation shale using nitrogen adsorption analysis. J Nat Gas Sci Eng 27:402-409

Liu T, Zhang X, Li Z, Chen Z (2014) Research on the homogeneity of asphalt pavement quality using X-ray computed tomography (CT) and fractal theory. Constr Build Mater 68:587-598

Liu X, Xiong J, Liang L (2015) Investigation of pore structure and fractal characteristics of organic-rich Yanchang formation shale in central China by nitrogen adsorption/desorption analysis. J Nat Gas Sci Eng 22:62-72

Loucks RG, Reed RM, Ruppel SC, Hammes U (2012) Spectrum of pore types and networks in mudrocks and a descriptive classification for matrix-related mudrock pores. AAPG Bull 96(6):1071-1098

Lours T, Zarzycki J, Craievich A, Dos Santos DI, Aegerter M (1988) A SAXS study of kinetics of aggregation of silica sols. J Non Cryst Solids 100(1-3):207-210

Ma L, Lin C, Fan M (2012) Quantitative classification and evaluation of reservoirs based on fractal features of micro-pore structures. J Oil Gas Technol 34(5):15-19

Mandelbrot BB (1982) The fractal geometry of nature. W. H. Freeman $\&$ Co, New York

Mastalerz M, He L, Melnichenko YB, Rupp JA (2012) Porosity of coal and shale: insights from gas adsorption and SANS/USANS techniques. Energy Fuel 26:5109-5120

Pyun SI, Rhee CK (2004) An investigation of fractal characteristics of mesoporous carbon electrodes with various pore structures. Electrochim Acta 49(24):4171-4180

Qi H, Ma J, Wong PZ (2002) Adsorption isotherms of fractal surfaces. Colloid Surf A 206(1-3):401-407

Qiu X, Tan S, Dejam M, Adidharma H (2019) Simple and accurate isochoric differential scanning calorimeter measurements: phase transitions for pure fluids and mixtures in nanopores. Phys Chem Chem Phys 21(1):224-231

Romero-Sarmiento M-F, Ducros M, Carpentier B, Lorant F, Cacas M-C, Pegaz-Fiornet S, Wolf S, Rohais S, Moretti I (2013) Quantitative evaluation of TOC, organic porosity and gas retention distribution in a gas shale play using petroleum system modeling: application to the Mississippian Barnett Shale. Mar Pet Geol 45:315-330

Sing KSW (2004) Characterization of porous materials: past, present and future. Colloid Surf A 241(1-3):3-7
Sing KSW, Evertt DH, Haul RAW, Moscou L, Pierotti RA, Rouquerol J, Siemieniewska T (1985) Reporting physisorption data for gas solid systems with special reference to the determination of surface-area and porosity. Pure Appl Chem 57(4):603-619

Sun L, Tuo J, Zhang M, Wu C, Wang Z, Zheng Y (2015) Formation and development of the pore structure in Chang 7 member oil-shale from Ordos Basin during organic matter evolution induced by hydrous pyrolysis. Fuel 158:549-557

Tan S, Qiu X, Dejam M, Adidharma H (2019) Critical point of fluid confined in nanopores: experimental detection and measurement. J Phys Chem C 123(15):9824-9830

Tiwari P, Deo M, Lin CL, Miller JD (2013) Characterization of oil shale pore structure before and after pyrolysis by using X-ray micro CT. Fuel 107:547-554

Wang C, Hao S, Sun W, Chu W (2012) Fractal dimension of coal particles and their $\mathrm{CH} 4$ adsorption. Int J Min Sci Technol 22(6):855-858

Wang M, Xue H, Tian S, Wilkins RWT, Wang Z (2015) Fractal characteristics of Upper Cretaceous lacustrine shale from the Songliao Basin, NE China. Mar Pet Geol 67:144-153

Wei M, Duan Y, Dong M, Fang Q, Dejam M (2019) Transient production decline behavior analysis for a multi-fractured horizontal well with discrete fracture networks in shale gas reservoirs. J Porous Media 22(3):343-361

Yang F, Ning Z, Liu H (2014a) Fractal characteristics of shales from a shale gas reservoir in the Sichuan Basin, China. Fuel 115:378-384

Yang F, Ning Z, Wang Q, Kong D, Peng K, Xiao L (2014b) Fractal characteristics of nanopores in shales. Nat Gas Geosci 25(4):618-623

Yao Y, Liu D, Tang D, Tang S, Huang W (2008) Fractal characterization of adsorption-pores of coals from North China: an investigation on $\mathrm{CH} 4$ adsorption capacity of coals. Int J Coal Geol 73(1):27-42

Yao Y, Liu D, Tang D, Tang S, Huang W, Liu Z, Che Y (2009) Fractal characterization of seepage-pores of coals from china: an investigation on permeability of coals. Comput Geosci 35(6):1159-1166

Zhang L, Ji Y, Ma W, Zhang H (1998) Characteristics of fractional geometry and reservoir evaluation of fore mountain belt at Begedashan. J U Pet China (Edit Nat Sci) 22(5):31-33

Zhang S, Tang S, Tang D, Huang W, Pan Z (2014) Determining fractal dimensions of coal pores by FHH model: problems and effects. J Nat Gas Sci Eng 21:929-939

Zhang L, Kou Z, Wang H, Zhao Y, Dejam M, Guo J, Du J (2018) Performance analysis for a model of a multi-wing hydraulically fractured vertical well in a coalbed methane gas reservoir. J Pet Sci Eng 166:104-120

Zhao Y, Qu F, Wan Z, Zhang Y, Liang W, Meng Q (2010) Experimental investigation on correlation between permeability variation and pore structure during coal pyrolysis. Transp Porous Med 82(2):401-412

Publisher's Note Springer Nature remains neutral with regard to jurisdictional claims in published maps and institutional affiliations. 